\title{
EL RETRATO DE ISTOLACIO, INDORTES Y ORISSÓN EN LOS MANUALES ESCOLARES, Y EN LAS PUBLICACIONES PERIÓDICAS DEL SIGLO XIX
}

\author{
María Silas García Conde \\ Investigadora agregada del Instituto de Estudios Riojanos \\ silasgarciaconde@me.com
}

RESUMEN: En el siglo XIX España está consolidando su identidad nacional y para ello se sirve de los viejos héroes de la antigüedad. El propósito de este trabajo es analizar el uso de las figuras de Istolacio, Indortes y Orissón en los libros escolares, en los periódicos y en las revistas, para conocer el papel que jugaron los tres líderes hispanos en la construcción de una nueva historia nacional y en la consolidación de la imagen que los españoles tenían de sí mismos durante esta centuria.

Palabras clave: Istolacio, Indortes, Orissón, historia nacional, manuales escolares.

\section{THE PORTRAIT OF ISTOLACIO, INDORTES AND ORISSÓN IN SCHOOL TEXTBOOKS AND IN THE REGULAR PUBLICATIONS OF THE $19^{\text {TH }}$ CENTURY}

ABSTRACT: In the $19^{\text {th }}$ century Spain is consolidating its national identity, making use of the old heroes of antiquity. The aim of this paper is to analyze the presentation of the characters of Istolacio, Indortes and Orissón provided by school textbooks, newspapers and magazines, showing the role that these three Spanish leaders played in the new national history and their contribution to the creation of the Spanish self-identity during this century.

Keywords: Istolacio, Indortes, Orissón, national history, school textbooks.

Enviado: 31 de mayo de 2019 Aceptado: 16 de septiembre de 2019 
La historia de España del siglo XIX necesita a los viejos héroes de la Antigüedad para recuperar un imperio que se desmorona, y los utiliza en su tarea de rehacer el pasado y construir a medida una nueva y renovada identidad patriótica. Istolacio, Indortes y Orissón se van a convertir en los primeros caudillos hispanos que forman parte de ese grupo de personajes de la Antigüedad que contribuyeron a crear una nueva identidad nacional. Tres figuras cuyo recorrido histórico parece haber sido seleccionado convenientemente para adaptarse a los nuevos intereses nacionalistas de la España decimonónica.

Analizaremos en este trabajo la figura de los tres caudillos, para ello utilizaremos como referencia su recorrido histórico en las fuentes clásicas y estudiaremos su retrato en los manuales escolares y en las publicaciones periódicas del siglo XIX. Se trata de tres héroes rescatados por y para la historia de España de esa época que van a personalizar la resistencia hispana contra el invasor y se van a convertir en piezas fundamentales del discurso nacionalista. ${ }^{1}$

Los tres caudillos representan los valores genuinamente hispanos que los manuales logran transmitir a los escolares, mientras el incremento de las publicaciones periódicas durante el XIX despierta la conciencia cívica y nacionalista de un pueblo que comienza a sentirse parte integrante y activa de la nueva nación española. ${ }^{2}$ Son estos los documentos clave en los que nos vamos a apoyar para ayudar a entender el proceso que se siguió a la hora de reconstruir su imagen, y de adaptarla a las necesidades de los españoles del siglo XIX.

En este análisis ocupan un lugar relevante los errores que, intencionados o no, forman parte de la mentalidad colectiva de los españoles. Se tienen además muy presentes los hechos que preocupaban a unos ciudadanos de un país que se identificaba con los tres caudillos, y que se sirvieron de ellos para consolidar la imagen que tenían de sí mismos en un período clave de nuestra historia nacional.

Un primer elemento que nos proporciona la información que necesitamos sobre los tres hispanos y sobre los hechos que protagonizaron es el análisis de las fuentes clásicas. ${ }^{3}$ Los pocos datos históricos que nos han llegado sobre ellos

1. Aguilera Durán, T., "Héroes huidizos y traicioneros. Los hispanos de la segunda guerra púnica en el imaginario nacionalista", en Aldea Celada, J. M., Ortega Martínez, P., Pérez Miranda, I. y Soto García, Reyes., Historia, identidad y alteridad. Actas del III Congreso Interdisciplinar de Jóvenes Historiadores, Hergar, ediciones Antema, Salamanca, 2012, p. 441.

2. La prensa es un elemento que genera opinión, que tiene gran influencia sobre la población y que estará en manos de las élites culturales hasta que la implantación del liberalismo la convierta en un instrumento de educación popular y en una herramienta política (Fuentes, J. F. y Fernández Sebastián, J., Historia del periodismo español, Síntesis, Madrid, 1997, p. 66).

3. Polibio (2.1.5-6.) dice que los cartagineses, una vez solucionados "los asuntos de África", envían a Amílcar a la península para recobrar el dominio de esta. Tito Livio, por su parte, se centra en las tribulaciones de Amílcar por la pérdida de Sicilia y por el hecho de que Roma se había apoderado de la isla de Cerdeña mientras el cartaginés estaba ocupado sofocando la rebelión de los mercenarios (Liv. 21.1.5); cuenta, además, cómo Amílcar actuó en la península con el objetivo de incrementar el poderío cartaginés y teniendo in mente una guerra de mayor 
proceden de fuentes filocartaginesas y no contemporáneas a los hechos que narran. Estos hechos nos permiten señalar dos puntos de partida que nos ayudan a entender el papel que desempeñaron estos personajes dentro de su contexto histórico: las razones que empujaron a Amílcar a desembarcar en la península en el 237 a. C. ${ }^{4}$, y cómo sucedió el enfrentamiento bélico entre las tropas hispanas y el ejército cartaginés.

La Primera Guerra Púnica dejó al descubierto los problemas económicos de un imperio que, derrotado y humillado por el ejército romano, buscaba reafirmar su posición en el Mediterráneo, acceder a los recursos de la península ibérica, y solucionar sus problemas económicos. Es en ese contexto donde entendemos el desembarco de Amílcar en Cádiz y su intención de mantener bajo control las factorías del sudeste y las minas de oro y plata de Sierra Morena. ${ }^{5}$

Gracias a Diodoro Sículo sabemos cómo se desarrolló el enfrentamiento entre los púnicos y los pueblos hispanos. El desembarco de Amílcar, sus avances militares por la cuenca baja del Guadalquivir y su choque con los turdetanos bajo el mando de Istolacio e Indortes, ${ }^{6}$ que contaron también con tropas de origen celtíbero, ${ }^{7}$ se saldó con una estrepitosa derrota. Los dos caudillos sufrirán las consecuencias: Istolacio será crucificado tras ser torturado e Indortes, que intentó huir y refugiarse en una colina para poder decidir con ventaja su siguiente movimiento, será capturado torturado y crucificado por el líder cartaginés, que además le extraerá los ojos antes del suplicio. ${ }^{8}$

El cruel comportamiento de Amílcar con los líderes hispanos nos permite entender precisamente un elemento clave que ya hemos mencionado y que afecta de manera directa a la historia militar púnica: la falta de liquidez había empujado a los cartagineses a buscar nuevos recursos en la península y uno de

alcance que será protagonizada más adelante por Aníbal (Liv. 21.2.1-2.). Apiano (Ib. 4), por último, ofrece detalles sobre el alcance del poder de la familia Barca en el Senado cartaginés, sobre todo cuando cuente cómo Amílcar, gracias al apoyo de su yerno, se había librado de comparecer en el Senado para responder de los perjuicios ocasionados por la Primera Guerra Púnica y cómo había conseguido, junto con Hannón, ser nombrado general para hacer frente a la sublevación númida. También va a indicar que, cuando Hannon sea reclamado por el Senado para responder sobre unas acusaciones en su contra, Amílcar se quedará sólo al frente del ejército, y aprovechará para cruzar hasta Gades y emprender la expansión púnica en Iberia (Ib. 5).

4. Diod. Sic. 25.10; Plb. 2. 1. 5; App. Ib. 5.

5. Para Cartago era importante restablecer por medios militares el control sobre el comercio de los metales, lo que explica la elección de Gadir para el desembarco de tropas, un buen punto de partida para penetrar en el valle del Guadalquivir y en las regiones mineras de Sierra Morena. (González Wagner, C., "Los Bárcidas y la conquista de la península ibérica". Gerion 17, 1999, p. 265).

6. Diod. Sic. 25.10.1-3.

7. Bendala Galán, M., Hijos del Rayo, los Barca y el dominio cartaginés en Hispania, Trébede ediciones, Madrid, 2005, p. 40.

8. Diod. Sic. 25.10.1-3. 
los objetivos clave de Amílcar será conseguir los recursos necesarios con los que poder sufragar los gastos de su ejército y evitar así una nueva revuelta de los mercenarios. ${ }^{9}$ Es por ese motivo que el control de un territorio rico en plata, que le iba a permitir tanto pagar a los soldados como asegurar la supervivencia del maltrecho imperio cartaginés, justificaba a ojos de sus hombres y del propio general púnico dicha conducta.

El tercer héroe al frente de lo que Diodoro consideraba la revancha ibérica es Orissón: un caudillo que acudió en ayuda de la ciudad de Heliké, sitiada por Amílcar, hizo huir al ejército enemigo y se convirtió en el responsable directo de la muerte de general cartaginés. ${ }^{10}$ Un episodio que Apiano atribuye a una estrategia urdida por los íberos, que incendiaron unos carros con bueyes y los lanzaron contra sus enemigos. Una treta que distrajo hasta tal punto a las tropas cartaginesas que permitió a los íberos disolver la formación enemiga, abalanzarse sobre su ejército y acabar con Amílcar. ${ }^{11}$ Sin embargo, este rey anónimo cuyo origen situamos en la región de la Oretania parece que no compartió el mismo destino que sufrieron los otros dos caudillos celtíberos. ${ }^{12}$

De todas estas referencias históricas concluimos que los datos que nos proporcionan las fuentes clásicas, además de ser escasos, no nos facilitan un conocimiento objetivo de tres héroes hispanos. Será en el siglo XIX cuando La Historia General de España de Modesto Lafuente los convierta en parte del imaginario del espíritu independentista hispano. Cuando estos personajes, que en la Antigüedad no poseían una gran relevancia histórica, y a los que apenas se menciona en las fuentes clásicas, se conviertan en piezas clave con las que sustentar los discursos en clave nacionalista.

El objetivo de Modesto Lafuente era señalar a través de los acontecimientos la esencia de la nación. Para lograr este propósito fijó gran parte de los mitos nacionales, como Numancia, Sagunto y Viriato, y exaltó todo aquello que contribuía a la defensa frente a lo extranjero, a la lucha del pueblo español por su independencia. ${ }^{13}$ Los tres líderes hispanos deben a este autor, considerado

9. Al finalizar la Primera Guerra Púnica el contingente de mercenarios que formaba parte del ejército es fue desmovilizado y enviado a África a la espera de una paga que no llegaba. Estalla entonces una revuelta y Amílcar es elegido por el senado para hacer frente a la crisis asumiendo el papel de un líder capaz de resolver cualquier tipo de problema. (Liv. 21.1.5.).

10. Diod. 25. 10. 3-4.

11. App. Ib. 5.

12. Sobre este rey, vid. Moret, P., "Los monarcas ibéricos en Polibio y Tito Livio", en Quesada Sanz, F., Monet, P. y Bendala Galán, M. (coords.), Cuadernos de prehistoria y arqueología 28/29 (2002-2003), p. 31, y Gonzalbes Cravioto, E., "Helice y la muerte de Amílcar Barca", en Sanz Gamo, R. (coord.), Il Congreso de Historia de Albacete, Instituto de estudios albacetenses Don Juan Manuel, Albacete, 2002 p. 207.

13. López Vela, R., "De Numancia a Zaragoza. La construcción del pasado nacional en las Historias de España del ochocientos", en García Cárcel, R. (coord.), La construcción de las historias de España, Marcial Pons, Madrid, 2004, p. 207. 
como el principal responsable de rescatar a los héroes de la Antigüedad de las fuentes clásicas, el hecho de haberse convertido en fieles representantes del espíritu independentista hispano.

En su obra, Istolacio, Indortes y Orissón dejan de formar parte de la coalición que se enfrentó a Amílcar para liderar el movimiento de resistencia contra la dominación extranjera. Se les describe como "fogosos" y "poseedores de "una energía feroz", pero sin habilidad para resistir el ataque de tropas disciplinadas. Están al frente y personalizan "la primera y desgraciada tentativa de independencia" de las muchas que los españoles llevaron a cabo en su largo y dilatado recorrido histórico. ${ }^{14}$

Una nueva imagen de los tres líderes hispanos que los manuales de escuela decimonónicos heredan de una obra que fue todo un éxito entre los medios no académicos hasta las primera décadas del siglo XX, y que además de ayudar a consolidar la identidad de la nueva nación española supondrá un antes y un después en la selección de los temas que van a formar parte de los libros de texto.

En un período en el que conviven los usos del Antiguo régimen con las nuevas corrientes pedagógicas que Ilegan a la península, las nuevas ideas se recogen en los manuales y se hacen evidentes en la selección de los contenidos de los libros de texto: corrientes pedagógicas como el positivismo de Herbert Spencer, que influye en la orientación pedagógica de la Institución Libre de Enseñanza, o el internacionalismo y la renovación pedagógica ideada por el obrerismo, que influirá en la reorientación académica de los ateneos y los centros obreros de nuestro país. ${ }^{15}$

La entrada en vigor de la Ley Moyano en 1857 establece unas pautas mínimas para poner en marcha una escuela nacional en la que hay de entrada una falta de interés a la hora de establecer los contenidos de los manuales. Todo esto cambia cuando el Estado reconoce a partir de 1875 que es su responsabilidad garantizar las condiciones didácticas de los libros de texto, con medidas como la creación del Museo de Instrucción Primaria en Madrid, ${ }^{16}$ donde se recogerán los objetos, el material científico y los textos escolares que podrán así ser revisados previa y posteriormente a su publicación. ${ }^{17}$

14. Lafuente, M., Historia General de España desde los tiempos primitivos hasta la muerte de Fernando VII, tomo I., Montaner y Simon editores, Barcelona, 1883, p. 61.

15. González Agapito, J., "Sobre el influjo de la educación europea en España" en Ruiz Berrio, J., Bernat, A., Domínguez, R. y Juan, V. M. (eds.), La educación en España a examen (1898-1998): Jornadas nacionales en conmemoración del centenario del noventa y ocho, vol. 2, Ministerio de Educación y Cultura, Instituto Fernando El Católico, Diputación de Zaragoza, Madrid-Zaragoza, 1999, p. 205.

16. Se establecen medidas como la creación de un museo de instrucción primaria en Madrid (Real Decreto creando en Madrid un museo de Instrucción Primaria, Gaceta de Madrid 127, 7 de mayo de 1882, p. 384).

17. García Conde, S. (2019), Hispania en la Escuela: La conquista romana de Hispania en los manuales escolares (1875-1970). Tesis inédita. Universidad del País Vasco, p. 62. 
Es por ese motivo que vamos a distinguir entre los contenidos de los primeros manuales, donde no se tenía en cuenta la idoneidad o no de este tipo de material, y aquellos que se publicaron después, basados en el concepto nacionalista de la historia de España de Modesto Lafuente.

Respecto al primer grupo, señalamos la ausencia de referencias a los tres héroes hispanos, en relatos como el Compendio de historia de España de Tenorio editado en 1844 o en Las lecciones instructivas de la historia y la geografía de Tomás de Iriarte en 1860. Pero son los dos primeros, Istolacio e Indortes, los que se eliminan de manera recurrente en los libros de texto, mientras que en algunos manuales sí aparecen referencias a Orissón. Es el caso de la Nueva historia de España para los niños de Luis García Sanz editado en 1845, o el Prontuario de Historia de España de Ángel María Terradillos en 1848, que eliminan a Istolacio y a Indortes de sus contenidos y se centran en Orissón, por ser el que venció a Amílcar ${ }^{18}$ y el que consiguió que los púnicos no pudiesen subyugar a los celtíberos. $^{19}$

La implantación definitiva de la escuela nacional y, tal y como ya señalamos, la difusión de la obra de Modesto Lafuente, influyen de manera directa en los contenidos de los libros de texto. Las ideas que este autor difunde son las que definen a esa nueva generación de españoles, que aprenden en la escuela lo que necesitan y que son capaces de construir su propia identidad nacional. Ese es el motivo de que los contenidos sobre los tres héroes hispanos que se recogen en los libros de texto del último tercio del siglo XIX se basen en los estereotipos que este autor propone en su Historia General de España desde los tiempos primitivos hasta la muerte de Fernando $\mathrm{VII}^{20}$.

Textos que abogan por la necesidad de conseguir "unos criterios y una imagen histórico-nacionales" ${ }^{21}$, apelando precisamente a la memoria histórica de los españoles, a lo que se suman los nuevos criterios en la publicación de los libros de texto: no se trata solo de narrar de forma lineal los hechos históricos, el libro tiene que indicar al alumno las razones por las que los caudillos decidieron tomar las armas y enfrentarse a los púnicos. Unos motivos que, según la Historia de España en verso corregida y aumentada hasta 1890 de Antonio Anguiz, responden a la necesidad de dar una respuesta a los abusos

18. García Sanz, L., Nueva historia de España para los niños. Impr. Rufino, Madrid, 1845, p. 11.

19. Terradillos, A. M., Prontuario de historia de España; aprobado por el gobierno dispuesto en dialogo para facilitar su estudio, $2^{a}$ edición enteramente corregida, Imprenta de Gregorio Hernando, Madrid, 1848, p. 12.

20. López Facal, R., "Enseñanza de la historia y formación de la identidad nacional", en Estepa Giménez, J., Friera Suarez, F. y Piñeiro Peleteiro, R., Identidades y territorio: un reto para la didáctica de las Ciencias Sociales, Asociación Universitaria de Profesores de Didáctica de las Ciencias Sociales, Oviedo, 2001, p. 151.

21. López Vela, R., “De Numancia a Zaragoza..., p. 199. 
de los cartagineses en el territorio, ${ }^{22}$ mientras que en la cartilla de Historia de España para uso de las escuelas de niñas de Monreal de Lozano y editada en 1887 se indica el interés partidista de reivindicar la independencia de la península. ${ }^{23}$ En esta obra los caudillos hispanos se convierten así en responsables, en frases como "fueron los primeros jefes que lucharon por la independencia de su patria". ${ }^{24}$

Se va a identificar la presencia púnica con una tiranía que va a obligar a los caudillos hispanos a tomar las armas. Vemos un ejemplo de esto último en la historia de España de Anselmo Salvá y Pérez editado en 1896, donde a la pregunta de si los españoles soportaron la conquista de los cartagineses se ofrece como respuesta la sublevación hispana a manos de Indortes e Istolacio, es decir, una respuesta claramente negativa al dominio de lo extranjero. ${ }^{25}$

La reivindicación del territorio como propio es otro de los argumentos de la obra de Modesto Lafuente, que interesa que se transmita también a través de los libros de texto. En el libro Elementos de Historia de España de Ana Arizmendi de Sanz editado en 1897, Indortes e Istolacio son bautizados como "Ios primeros héroes de nuestra independencia" cuya muerte prematura a manos del invasor cartaginés va a ser vengada por Orissón. ${ }^{26}$

Ocurre algo similar en el libro de Emilio Morera Llauradó, Compendio de Historia de España distribuido en lecciones (1891), en el que Istolacio e Indortes vuelven a ser "los primeros héroes de nuestra independencia" que van a oponer "una seria resistencia, sucumbiendo a las huestes enemigas" mientras la "sangre derramada de las víctimas" será vengada más tarde por otro caudillo al que no se identifica en el texto, pero que sería Orissón. ${ }^{27}$

En ninguno de estos libros de texto se discute ni el hecho de que Indortes e Istolacio murieran a manos de Amílcar, ni tampoco la muerte de Amílcar a manos de Orissón. Lo que sí nos interesa, porque es muy evidente en los manuales, es la manipulación en los textos de estas muertes para así conseguir dar

22. Roca y Cornet, J. y Anguiz, A., Historia de España en verso por Joaquín Roca y Cornet; refundida y aumentada desde 1857 hasta nuestros días por Antonio Anguiz. Libr. de Antonio J. Bastinos, Barcelona, 1890, p. 13.

23. Monreal de Lozano, L. C., Cartilla de historia de España para uso de las escuelas de niñas por Luciana Casilda Monreal, Impr. de Pedro Ortega, Barcelona, 1887, p. 20.

24. Monreal de Lozano, L. C., Cartilla de historia de España para uso..., p. 20.

25. Salvá Pérez, A., Resumen de historia de España para uso de los niños en las escuelas por A. Salvá, novísima edición ilustrada. Imprenta y librería de Hijos de Santiago y Rodríguez, Burgos, 1896, p. 12.

26. Arizmendi de Sanz, A., Elementos de historia de España, Librería de hijos del Campo, Sevilla, 1897, p. 16.

27. Morera Llaurado, E., Compendio de la historia de España; distribuido en lecciones para uso de los alumnos de la Segunda Enseñanza, escuelas normales y seminarios conciliares por Emilio Morera y Llauradó, Establecimiento tipográfico de Adolfo Alegret, Tarragona, 1891, p. 25. 
un "halo heroico" a los personajes. Nos vamos a encontrar dos formas de narrar la muerte de los caudillos, la primera, más aséptica, nos indica su muerte ante "las aguerridas huestes enemigas", ${ }^{28}$ omitiendo la forma en la que esta se va a producir; la segunda, más gráfica, va a hacer del martirio de los dos caudillos en la cruz el eje de su trascendencia como héroes.

La razón que explica la segunda versión del relato resulta bastante obvia: la muerte de Istolacio en el campo de batalla es épica pero no vistosa, y la ejecución de Indortes, después de haber huido sin presentar batalla, es un motivo de escarnio. Sin embargo, si la intención es presentarlos como mártires de la independencia, la crucifixión les hace encajar más en el papel que van a representar. $^{29}$

Se trataba, en definitiva, de transmitir un mensaje nacionalista en el que tanto Istolacio e Indortes como Orissón dejaban de estar al frente de los turdetanos y de los oretanos para defender la independencia de la patria. Tres hombres que no van a saber resolver el ataque de un ejército invasor como el púnico, pero que van a representar lo que necesitan los habitantes de la nueva España liberal, el espíritu de una nación que sabe reivindicar lo que es suyo y que se va a defender en una lucha sin cuartel frente a todo lo que venga de fuera y que pretenda dominar el territorio nacional.

El aumento de las tiradas de los periódicos y las revistas se vio favorecido por la permisividad de las leyes de imprenta de inicios de siglo, lo que contribuyó al auge de las publicaciones periódicas que se convirtieron en el principal medio de comunicación de este período. ${ }^{30}$ Es ahora cuando los hombres del siglo XIX verán en estas publicaciones una manera de tomar conciencia de lo que les rodea y de sentirse parte activa de una nueva comunidad cívica. ${ }^{31}$ La calle multiplicará el impacto de la prensa en la ciudadanía, que accederá a ella en los gabinetes, que escuchará las noticias en las tertulias y que se adaptará al nuevo ritmo de vida que impone la burguesía. ${ }^{32}$

Esos mismos periódicos y revistas van a utilizar en sus páginas la imagen de Indortes, Istolacio y Orissón, y los van a convertir, al igual que ya ocurría en los manuales escolares, en símbolos de independencia. Basta mencionar dos

28. En el libro de Morera Llauradó los héroes no son asesinados, sino que sucumben ante las huestes enemigas, y será Orissón el encargado de vengarlos (Morera Llaurado, E., Compendio de la historia de España; distribuido en lecciones..., p. 25).

29. García Conde, S., Hispania en la escuela, p. 197.

30. La constitución de 1812 reconoce por primera vez en España la libertad de imprenta, aunque será antes, en plena invasión francesa cuando Álvaro Flórez Estrada, redacte un escrito a las autoridades españolas en rebeldía apelando precisamente a esa necesidad. (Barrera, C. (ed.), El periodismo español en su historia, Ariel Prácticum, Barcelona, 2000, p. 16).

31. Francisco Fuentes, F. J. y Fernández Sebastián, J. Historia del..., p. 48.

32. Valls, J. F., Prensa y burguesía en el s. XIX español, colección historias, ideas y textos, Anthropos, Barcelona, 1988, p. 83. 
ejemplos: en un artículo titulado "Del porvenir de nuestra raza" y publicado en La América, crónica hispanoamericana, ${ }^{33}$ el 24 de junio de 1857, solo unos años después de que lo hiciera el primer volumen de la Historia general de España de Modesto Lafuente, leemos que los tres caudillos se convirtieron en los ejemplos de "las inmortales hazañas" que protagonizaron los españoles. ${ }^{34}$ Un artículo que sirve a su autor, Emilio Castelar, para plantear la necesidad de crear una confederación en la que la nueva raza latina, liderada por España, pudiera enfrentarse con garantías a la expansión anglosajona de los Estados Unidos. ${ }^{35}$

También relacionado con este sentimiento de independencia, el artículo titulado "Las cruces, historia, tradición y costumbres" publicado por Benito Mas y Prat en La Ilustración española y americana el 8 de enero de 1881, explica a los lectores que la muerte en la cruz de Istolacio e Indortes ratificó nuestro sentimiento de pertenencia a la nación española, y que la primera vez que este tipo de ejecución apareció en nuestra historia fue cuando Amílcar ordenó crucificar a Istolacio e Indortes, unos hechos que consiguieron que se reafirmara por primera vez nuestro sentimiento patriótico. ${ }^{36}$ Un artículo en el que se describe la fiesta de la cruz de Mayo, una fiesta muy arraigada en Andalucía donde conviven el sentimiento religioso y las tradiciones populares. ${ }^{37}$

Pero dejando al margen las intenciones nacionalistas que se desprenden de estos artículos no van a faltar en este tipo de publicaciones tímidos intentos de encontrar una explicación razonada a la derrota de los tres líderes. La revista salmantina Adelante, en su número del 15 de febrero de 1880, analiza las razones que hicieron que los caudillos hispanos cayeran derrotados por las huestes de Amílcar y la encuentra en el hecho de que se vieron condicionados por el aislamiento en el que habían vivido hasta ese momento, que les impidió ofrecer la enérgica resistencia que necesitaban para lograr vencer al ejército púnico. ${ }^{38}$

33. Se trata de una publicación que comienza a editarse a mediados del s. XIX, de periodicidad quincenal que aprovecha la expansión económica de este período, que representa los intereses de una burguesía, y que intenta mejorar las relaciones comerciales de España con las repúblicas hispanoamericanas. (López Ocón, L., "La América. Crónica Hispanoamericana: Génesis y significación de una empresa americanista del liberalismo democrático español". Quinto centenario 4, 1982, p. 139).

34. Castelar, E., "Del porvenir de nuestra patria", La América, crónica hispanoamericana, 24 de junio 1897, p. 1.

35. Bustamante, J., Élites intelectuales y modelos colectivos; mundo ibérico (s. XVI-XIX), Consejo Superior de Investigaciones Científicas, Madrid, 2002. p. 291.

36. Mas y Prat, B., "Las cruces, historia, tradición y costumbres", La llustración Española y Americana, 8 de enero de 1881. pp. 18-19.

37. Para una mayor información sobre la fiesta de las cruces de mayo vid Rodríguez Becerra, S. "Las cruces de mayo en Andalucía. Historia y Antropología de una fiesta." En González Cruz, D. (coord.), Las cruces de mayo en España. Tradición y ritual festivo, Universidad de Huelva, Huelva, 1999, pp. 57-80.

38. M. G. "Recuerdos históricos", Adelante: revista salmantina de ciencias, arte, literatura e intereses materiales, 15 de febrero de 1880, pp. 2-3. 
El ejemplo de Istolacio e Indortes sirve además para que los periódicos apelen a la conciencia patriótica y a la unidad de los españoles, y lo hacen recordando que son la libertad de imprenta, el sufragio universal y los votos lo que hace libres a los hombres, y no el uso de las armas. Es el caso del artículo publicado el 3 de noviembre de 1869 en La Alianza del Pueblo, que intenta demostrar que, si Indortes e Istolacio se sacrificaron por vencer al cartaginés y pelearon por su libertad, el español que vive en 1869, que sabe lo que es una revolución y que está inmerso en el sexenio democrático, está obligado a oír la voz de su conciencia, porque es la voz de los mártires que en el pasado lucharon por su independencia. ${ }^{39}$

Unos héroes que también encuentran su hueco en la escultura, tal y como se indica en la revista La llustración Artística. ${ }^{40}$ En su número publicado el 18 de junio de 1883 se describe la obra de Medarno San Martín titulada "Independencia". Asegura el artículo que la obra ha conseguido despertar "el interés más vivo" evocando la figura de los caudillos celtíberos. Su mayor logro, según esta publicación, es la convicción, el entusiasmo y la energía de sus "indómitas cabezas", "de sus pechos palpitantes y del modo en que aquellos labios entreabiertos parecen querer dar el grito sublime de independencia" ${ }^{41}$ Un trabajo que según el Diario oficial de Avisos de Madrid del viernes 13 de junio consiguió un premio en la Exposición Nacional de Bellas Artes de 1884. ${ }^{42}$

San Martín, malogrado escultor de origen catalán, desempeñó en su juventud el oficio de escenógrafo y descubrió muy pronto que la escultura era lo que mejor se ajustaba a sus habilidades. Enviado con veintiséis años a Roma por la Diputación Provincial de Barcelona, será allí donde elabore la citada escultura sin perder por ello una personalidad propia que caracterizará toda su producción artística. ${ }^{43}$

La audacia de los caudillos hispanos aparece además en la retórica parlamentaria, y en concreto en una alocución de Castelar que reproduce El correo militar del 5 de mayo de 1886. Un discurso pronunciado en la inauguración del Centro del Ejército y de la Armada, la noche del 2 de mayo de 1886, y que el

39. "La historia dice que debemos defender nuestros derechos" La alianza del pueblo, periódico republicano de Salamanca, 3 de noviembre de 1869, p. 1.

40. Revista editada en Barcelona de 1882 a 1916 que estaba enfocada a un público interesado por el arte y las noticias artísticas. (Velasco Sánchez, J. T., "La llustración Artística (1882-1916) noticias artísticas y difusión del arte a través de esta revista", AACADigital 19, 2012, pp. 1-5).

41. "Independencia, copia de una escultura de D. M. Sanmarti", Ilustración Artística, 18 de junio de 1883, p. 195.

42. "Relación de los artistas premiados en la exposición nacional de bellas artes de 1884 y de las obras a que se han otorgado las recompensas", Diario oficial de avisos de Madrid, 13 de junio de 1884, p. 1.

43. Comas, Ramon N. "L' Esculptor Medard San Martí" La Veu de Catalunya 31, 9 de agosto de 1891, p. 365. 
periódico El Globo. Diario Ilustrado publicado el 3 de mayo de 1886 recoge en su portada de forma íntegra. ${ }^{44}$

Asegura el político que "dentro de cada hombre hay un soldado", y que, a lo largo de nuestra historia, donde tanto nos han enaltecido las armas, encontramos ejemplos de grandes hombres "como Indortes e Istolacio que se enfrentaron con su cuchillo y con su honda a la perfidia cartaginesa". ${ }^{45}$

Y el gran ejemplo de grandeza que los caudillos hispanos representan para los escolares del siglo XIX queda recogido en la Gaceta de Instrucción Pública del 5 de octubre de 1894. Se reproduce en ella el discurso que dio el niño Antonio de la Torre en la Alcaldía de Valladolid pidiendo a los héroes hispanos la inspiración y el amor a la patria que se necesitaban para poder afrontar los peligros estaban por venir, y enfrentarse así a los momentos de angustia cuando se viera amenazada nuestra independencia. ${ }^{46}$

Señalamos, ya para finalizar, que Istolacio, Indortes y Orissón, a los que apenas se menciona en las fuentes clásicas, reaparecen con fuerza durante el siglo XIX porque representan a esos grandes hombres que son capaces de pelear por su libertad y de sacrificarse por el bien común. Los tres forman parte del nuevo engranaje de la España nacionalista y cumplen una labor esencial, representar lo genuino y lo puro de la esencia española, en un momento clave, la primera vez que se luchó por la independencia de la península.

\section{Bibliografía}

Aguilera Durán, T., "Héroes huidizos y traicioneros. Los hispanos de la segunda guerra púnica en el imaginario nacionalista", en Aldea Celada, J. M., Ortega Martínez, P., Pérez Miranda, I. y Soto García, R., Historia, identidad y alteridad. Actas del III Congreso Interdisciplinar de Jóvenes Historiadores, Hergar, ediciones Antema, Salamanca, 2012, pp. 437-461.

Arizmendi de Sanz, A., Elementos de historia de España, Librería de hijos del Campo, Sevilla, 1897.

Barrera, C. (ed.), El periodismo español en su historia, Ariel Prácticum, Barcelona, 2000.

Bendala Galán, M., Hijos del Rayo, los Barca y el dominio cartaginés en Hispania, Trébede ediciones, Madrid, 2005.

44. Castelar, E., "Discurso pronunciado en la inauguración del Centro del Ejército y de la Armada la noche del 2 de mayo, por don Emilio Castelar", El Globo, diario ilustrado, 3 de mayo de 1886, p. 1.

45. "Las grandezas del ejército", El correo militar, diario de la tarde, defensor de los intereses del ejército y de la armada, tercera época, edición Madrid, 5 de mayo de 1886, p. 1.

46. "Asamblea pedagógica y exposición escolar de Valladolid", Gaceta de Instrucción pública periódico decenal, 5 de octubre de 1894, edición Madrid, p. 1474. 
Bustamante, J., Élites intelectuales y modelos colectivos; mundo ibérico (s. XVIXIX), CSIC, Madrid, 2002.

Fuentes, J. F. y Fernández Sebastián, J., Historia del periodismo español, Síntesis, Madrid, 1997.

García Conde. S., Hispania en la Escuela: La conquista romana de Hispania en los manuales escolares (1875-1970). Tesis doctoral inédita. Universidad del País Vasco, 2019.

García Sanz, L., Nueva historia de España para los niños. Impr. Rufino, Madrid, 1845.

Gonzalbes Cravioto, E., "Helice y la muerte de Amílcar Barca", en Sanz Gamo, R. (coord.), II Congreso de Historia de Albacete, Instituto de estudios albacetenses Don Juan Manuel, Albacete, 2002, pp. 203-211.

González Agapito, J., "Sobre el influjo de la educación europea en España" en Ruiz Berrio, J., Bernat, A., Domínguez, R. y Juan, V. M. (eds.), La educación en España a examen (1898-1998): Jornadas nacionales en conmemoración del centenario del noventa y ocho, vol. 2, Ministerio de Educación y Cultura, Instituto Fernando El Católico, Diputación de Zaragoza, Madrid-Zaragoza, 1999, pp. 203-212.

González Wagner, C., "Los Bárcidas y la conquista de la península ibérica". Gerion 17, 1999, pp. 263-294.

Iriarte, T. de y Andueza, J. M. de, Lecciones instructivas sobre la historia y la geografía obra póstuma de Tomás de Iriarte, 5a edición, Imprenta de Don Alejandro Gómez Fuentenegro, Málaga, 1860.

Lafuente, M., Historia General de España desde los tiempos primitivos hasta la muerte de Fernando VII, tomo I, Montaner y Simon editores, Barcelona, 1883.

López Facal, R., "Enseñanza de la historia y formación de la identidad nacional", en Estepa Giménez, J., Friera Suarez, F. y Piñeiro Peleteiro, R., Identidades y territorio: un reto para la didáctica de las Ciencias Sociales, Asociación Universitaria de Profesores de Didáctica de las Ciencias Sociales, Oviedo, 2001, pp. 145-169.

López Ocón, L., "La América. Crónica Hispanoamericana: Génesis y significación de una empresa americanista del liberalismo democrático español", Quinto centenario 4, 1982, pp. 137-174.

López Vela, R., “De Numancia a Zaragoza. La construcción del pasado nacional en las Historias de España del ochocientos", en García Cárcel, R. (coord.), La construcción de las historias de España, Marcial Pons, Madrid, 2004, pp. 195-298.

Monreal de Lozano, L. C., Cartilla de historia de España para uso de las escuelas de niñas por Luciana Casilda Monreal, Impr. de Pedro Ortega, Barcelona, 1887.

Morera Llaurado, E., Compendio de la historia de España; distribuido en lecciones para uso de los alumnos de la Segunda Enseñanza, escuelas normales y 
seminarios conciliares por Emilio Morera y Llauradó, Establecimiento tipográfico de Adolfo Alegret, Tarragona, 1891.

Moret, P., "Los monarcas ibéricos en Polibio y Tito Livio", en Quesada Sanz, F., Monet, P. y Bendala Galán, M. (coords.), Cuadernos de prehistoria y arqueología 28/29, 2002-2003, pp. 23-34.

Roca y Cornet, J. y Anguiz, A., Historia de España en verso por Joaquín Roca y Cornet; refundida y aumentada desde 1857 hasta nuestros días por Antonio Anguiz, Libr. de Antonio J. Bastinos, Barcelona, 1890.

Rodríguez Becerra, S. "Las cruces de mayo en Andalucía. Historia y Antropología de una fiesta", en González Cruz, D. (coord.), Las cruces de mayo en España. Tradición y ritual festivo, Universidad de Huelva, Huelva, 1999, pp. 57-80.

Salvá Pérez, A., Resumen de historia de España para uso de los niños en las escuelas por A. Salvá, novísima edición ilustrada. Imprenta y librería de Hijos de Santiago y Rodríguez, Burgos, 1896.

Terradillos, A. M., Prontuario de historia de España; aprobado por el gobierno dispuesto en dialogo para facilitar su estudio, 2a edición enteramente corregida, Imprenta de Gregorio Hernando, Madrid, 1848.

Valls, J. F., Prensa y burguesía en el s. XIX español, colección historias, ideas y textos, Anthropos, Barcelona, 1988.

Velasco Sánchez, J. T., "La Ilustración Artística (1882-1916) noticias artísticas y difusión del arte a través de esta revista", AACADigital 19, 2012, pp. 1-5.

\section{Publicaciones periódicas}

"Asamblea pedagógica y exposición escolar de Valladolid", Gaceta de Instrucción pública periódico decenal, edición Madrid, 5 de octubre de 1894, pp. 1473-1475.

"Independencia, copia de una escultura de D. M. Sanmarti", Ilustración Artística, 18 de junio de 1883, p. 195.

"La historia dice que debemos defender nuestros derechos" La alianza del pueblo, periódico republicano de Salamanca, 3 de noviembre de 1869, p. 1.

"Las grandezas del ejército", El correo militar, diario de la tarde, defensor de los intereses del ejército y de la armada, tercera época, edición Madrid, 5 de mayo de 1886, p. 1.

"Real Decreto creando en Madrid un museo de Instrucción Primaria", Gaceta de Madrid 127, 7 de mayo de 1882, p. 384.

"Relación de los artistas premiados en la exposición nacional de bellas artes de 1884 y de las obras a que se han otorgado las recompensas", Diario oficial de avisos de Madrid, 13 de junio de 1884, p. 1.

Castelar, E., "Del porvenir de nuestra patria", La América, crónica hispanoamericana, 24 de junio 1897, p. 1. 
Castelar, E., "Discurso pronunciado en la inauguración del Centro del Ejército y de la Armada la noche del 2 de mayo, por don Emilio Castelar", El Globo, diario ilustrado, 3 de mayo de 1886, p. 1.

Comas, Ramon N., "L'Esculptor Medard San Martí" La Veu de Catalunya 31, 9 de agosto de 1891, pp. 364-365.

M. G. "Recuerdos históricos", Adelante: revista salmantina de ciencias, arte, literatura e intereses materiales, 15 de febrero de 1880. pp. 2-3.

Mas y Prat, B., "Las cruces, historia, tradición y costumbres", La Ilustración Española y Americana, 8 de enero de 1881. pp. 18-19. 